\title{
Cytogenetic analysis of children with suspected genetic disorder
}

\author{
Shrestha $\mathrm{U}^{1}$, Bhattacharya $\mathrm{S}^{3}$, Bhatta $\mathrm{NK}^{4}$, Jha $\mathrm{CB}^{2}$ \\ ${ }^{1}$ Lecturer, Department of Human Anatomy, Universal college of Health Sciences, Bhairahawa, Nepal, ${ }^{3}$ Professor, \\ Department of Human Anatomy, ${ }^{4}$ Assistant Professor, Department of Paediatric, ${ }^{2}$ Associate Professor, Department of \\ Human Anatomy, B. P. Koirala Institute of Health Sciences, Dharan, Nepal
}

\begin{abstract}
Objectives: To analyze chromosomes in children with suspected genetic disorder and to categorize the chromosomal basis of genetic disorder

Materials and methods: Thirty children were selected from the patients attending genetic clinic, Department of Pediatrics, B.P. Koirala Institute of Health Sciences presenting with dysmorphic feature, mental retardation, short stature, congenital malformations and ambiguous genitalia with age between 0-15 years. Cytogenetic analysis was carried using standard peripheral blood lymphocyte culture method and G-banding technique in Cytogenetic laboratory of Department of Anatomy, B.P. Koirala Institute of Health Sciences.

Results: Chromosomal disorders were identified in $33.34 \%$ (10) of children. The most common chromosomal abnormality was Down syndrome (26.67\%) followed by Turner syndrome (6.67\%).

Conclusion: The cytogenetic analysis of children with suspected chromosomal aberration is important to uncover the contribution of chromosomal disorder in genesis of dysmorphisms, mental retardation, short stature, sexual ambiguity and congenital malformation in children and prevent further potentially unpleasant investigation being undertaken.
\end{abstract}

Key words: Chromosome, suspected genetic disorder, dysmorphic feature, mental retardation, short stature, congenital malformations, ambiguous genitalia

$\mathrm{G}$ enetic disorder is caused by defects in the inherited genetic material, which make up the chromosomes in a persons cell. Chromosomal disorders form a major category of genetic disorder accounting for a large proportion of all reproductive wastage, congenital malformations and mental retardation as well as it plays an important role in pathogenesis of malignancy. Each chromosomal disorder has its own history and clinical manifestations. The developmental disabilities, prenatal growth deficiency, short stature and microcephaly are phenotypic findings and distinctive enough to suspect genetic disorder. The phenotypes of chromosomal disorders vary considerably because of differences in the size of chromosome duplication or deficiency and the involvement of non-homologous chromosomes. Therefore, the cytogenetic analysis of children with suspected genetic disorder is important to establish a chromosomal diagnosis. Chromosomal diagnosis provides important information about prognosis and accurate information about the recurrence risk for future siblings. Information about the frequency of genetic disorders in the population as a whole is important for health care planning and provides a baseline data.

\section{Materials and methods}

Cytogenetic study was done in thirty children referred from the genetic clinic of B.P. Koirala Institute of Health Sciences with dysmorphic feature, mental retardation, short stature, congenital malformations and ambiguous genitalia aged between newborn to15 years.

Peripheral blood $(5 \mathrm{ml})$ was collected in a heparinized syringe in the cytogenetic laboratory and culture was done by using $5 \mathrm{ml}$ of Rosevill Park Medical Institute1640 (RPMI-1640) media, $1 \mathrm{ml}$ fetal calf serum and $0.1 \mathrm{ml}$ of Phytohemagglutinin. The culture vials were kept in an incubator for 72 hours at $37^{\circ} \mathrm{c} .50 \mu \mathrm{l}$ colcemid was added to arrest cell division at metaphase stage. Harvesting was done by adding $10 \mathrm{ml}$ of $\operatorname{KCL}(0.56 \%)$ for 20 minutes. The cells were fixed with fixative 3:1 (methanol: acetic acid) after discarding the supernatant. The slides were prepared and stained with $4 \%$ Giemsa stain. Twenty well spread metaphases were screened

\footnotetext{
Correspondence

Uttam Shrestha

Lecturer,

Department of Human Anatomy

Universal college of Health Sciences, Bhairahawa, Nepal

E-mail: uttam_bp30@hotmail.com
} 
under the light microscope x 100 magnification. Microphotography was done using automatic exposure. The exposed films (Kodak B/W) were developed and Karyogram was prepared by arranging homologous chromosomes in pairs according to international system for cytogenetic nomenclature (ISCN, 1995).

\section{Results}

The study was conducted in 30 children with age ranging from two days to 14 years having dysmorphic feature indicating specific chromosomal syndromes, mental retardation, short stature, ambiguous genitalia and congenital anomalies (Table 1).

Among 30 children, 12 children were suspected for Down syndrome, six children were suspected for Turner syndrome, 12 children were with congenital malformations such as cleft palate, congenital cataract, microcephaly, high arched palate, and common urogenital sinus with ectopic anus, ambiguous genitalia and other different malformations (Table 1).
The cytogenetic analysis confirmed Down syndrome in eight children (Fig 1). Among confirmed Down syndrome cases $(n=8)$ pure Down syndrome karyotype $(47, \mathrm{XX}+21$ or $47, \mathrm{XY}+21)$ was found in four cases $(50 \%)$ and remaining four cases $(50 \%)$ had mosaic karyotype (46, XX /47, XX +21). The male: female ratio was 5:3 among children with Down syndrome. Out of six suspected Turner syndrome children only two children were confirmed as Turner syndrome (45, $\mathrm{X})$ (Fig 2). Of these two children one $(50 \%)$ had pure Turner syndrome $(45, \mathrm{X})$ and another one $(50 \%)$ had mosaic Turner syndrome $(45, \mathrm{X} / 46, \mathrm{XX})$ (Table $1 \& 2)$. So out of 30 children with suspected genetic disorder, chromosome abnormality was found in $33.24 \%$ children, which included $26.67 \%$ of children with Down syndrome and $6.67 \%$ of children with Turner syndrome (Table 1). The remaining children showed normal karyotype.

Table1: Distribution of children

\begin{tabular}{|c|c|c|c|c|c|c|}
\hline \multirow{2}{*}{$\begin{array}{c}\text { Suspected genetic } \\
\text { disorder }\end{array}$} & \multicolumn{2}{|c|}{ Number of children referred } & \multicolumn{2}{c|}{ Number of children cytogenetically abnormal } \\
\cline { 2 - 8 } & Male & Female & Total & Male & Female & Total \\
\hline Down syndrome & 8 & 4 & 12 & 5 & 3 & 2 \\
\hline Turner syndrome & - & 6 & 6 & - & 2 & 0 \\
\hline $\begin{array}{c}\text { Other unknown } \\
\text { chromosomal } \\
\text { disorders }\end{array}$ & 7 & 5 & 12 & 0 & 0 & \\
\hline Total & 15 & 15 & 30 & 5 & 5 & \\
\hline
\end{tabular}

Table 2: Distribution of abnormal karyotypes

\begin{tabular}{|c|c|c|}
\hline Abnormal karyotypes & Chromosomal disorder & No. of cases \\
\hline $47, \mathrm{XY}+21$ & Pure Down syndrome & 2 \\
\hline $46, \mathrm{XY} / 47, \mathrm{XY}+21$ & Mosaic Down syndrome & 2 \\
\hline $46, \mathrm{XX} / 47, \mathrm{XX}+21$ & Mosaic Down syndrome & 1 \\
\hline $45, \mathrm{X}$ & Pure Turner syndrome & 1 \\
\hline $46, \mathrm{XX} / 45, \mathrm{X}$ & Mosaic Turner syndrome & \\
\hline
\end{tabular}




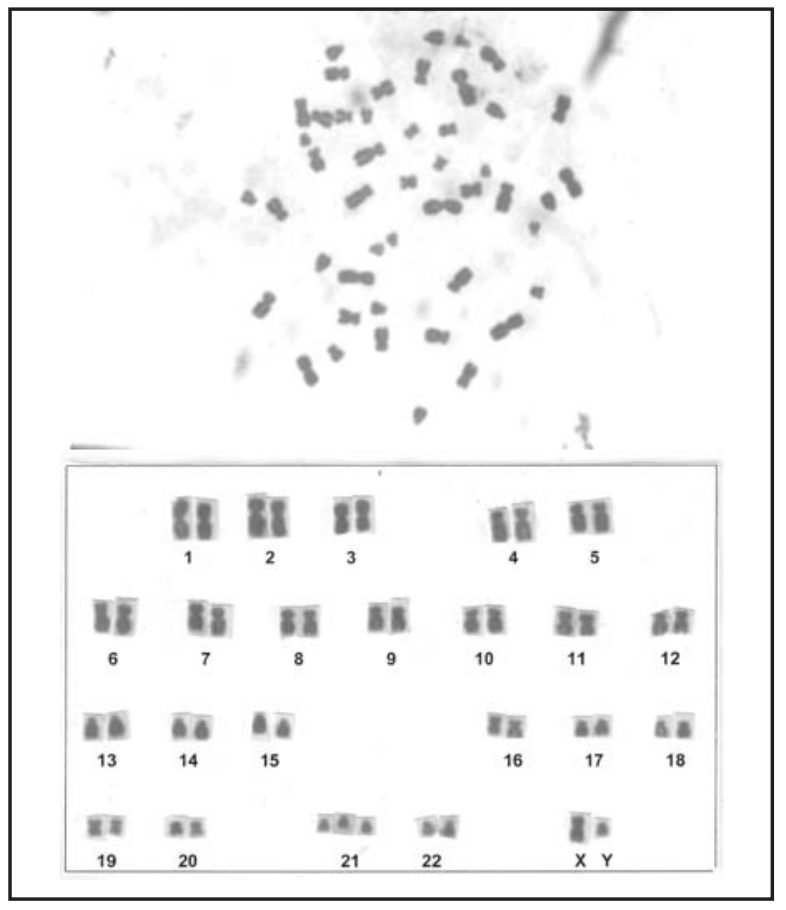

Fig 1: Photograph showing metaphase spread and karyotype of Down syndrome

\section{Discussion}

Chromosomal abnormalities have significant role in genesis of congenital malformations, mental retardation, short stature, sexual ambiguity and dysmorphic features in children. Down syndrome is the most common chromosomal aberrations leading to live births. It is usually diagnosed at birth or shortly thereafter by its dysmorphic features, which vary among patients but produce distinctive phenotype. In the present study, Down syndrome was suspected in children presenting with brachycephaly, oblique palpebral fissure, flat nasal bridge, low set folded ear, incurved fifth digit, hypotonia, protruding tongue and short neck. However, the physical examination of the syndrome was widely variable as shown by different studies ${ }^{1-3}$.

In this study, out of 12 children (suspected for the Down syndrome), the syndrome was diagnosed in $66.67 \%$ (8) of children after chromosomal analysis. Corties and Alliende 4 and Astete et $a l^{5}$ had also reported trisomy 21 only in $78 \%$ and $95.6 \%$ of cases suspected with Down syndrome respectively. In remaining four cases $(33.33 \%)$ of children the present study couldn't detect any chromosomal disorder. This could be due to undetected mosaicism for trisomy 21 or cryptic imbalance of chromosome 21 detectable by Fluorescence In Situ Hybridization (FISH), which was not possible in this laboratory. It has been reported ${ }^{6}$ that certain single gene disorders such as Zellweger syndrome, SmithMagenis syndrome bear some resemblance with Down

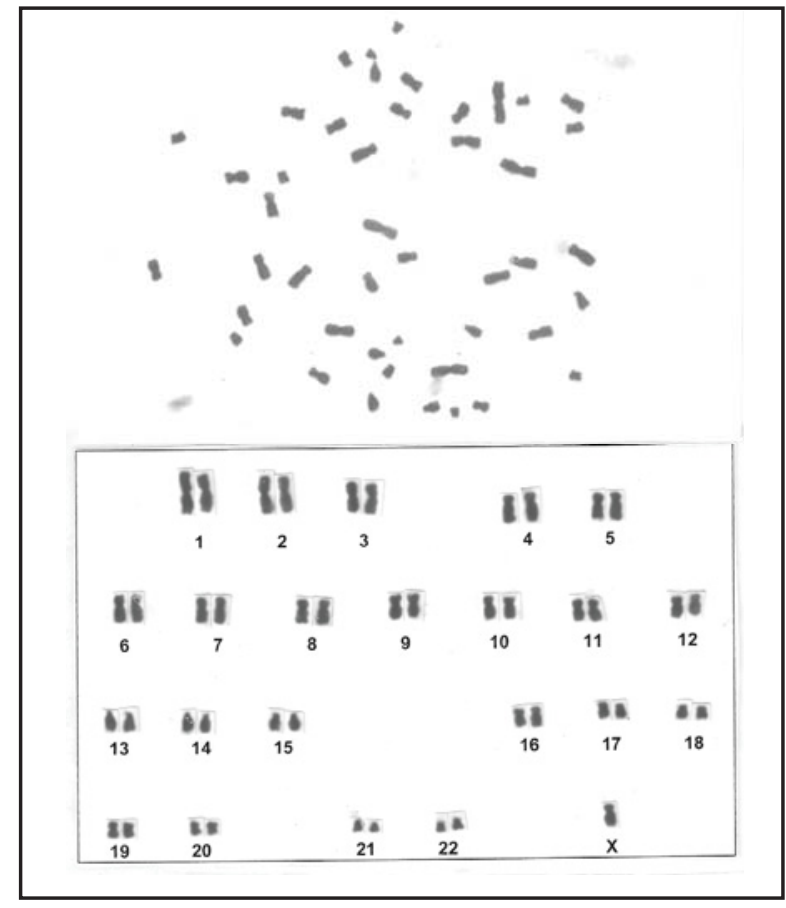

Fig 2: Photograph showing metaphase spread and karyotype of Turner syndrome

syndrome feature. Therefore comparatively higher number of cytogenetically undiagnosed cases in the present study could be due to wrong suspicion of these children of the Down syndrome. In our study among cytogenetically diagnosed Down syndrome $(n=8)$, $50 \%$ (4 cases) had pure Down syndrome karyotype $(47, \mathrm{XY}+21)$ and remaining $50 \%$ (4 cases) had mosaic Down syndrome karyotype (46,XX or XY / 47,XX or $\mathrm{XY}+21$ ) but Robertsonian translocation was not observed. However several studies had shown that most common chromosomal complement in Down syndrome cases is pure trisomy 21 (80\%-96.6\%) followed by Robertsonian translocation (1.7\%-7.67\%) and mosaic Down syndrome $(0.4 \%-9.4 \%)^{7,8,9}$. In our observation comparatively higher proportion of mosaic Down syndrome and smaller proportion of pure Down syndrome could be attributed to small sample size.

Turner syndrome is one of the chromosomal aberrations that can be recognized clinically during infancy or childhood based on short stature, broad shield chest, and lymph oedema of the lower limbs, and webbed neck ${ }^{10}$. In the present study Turner syndrome was suspected in those female children presenting with short stature, characteristic unusual facies, neck webbing, low posterior hairline and broad chest with widely spaced nipples. Out of six female cases (suspected for Turner syndrome), only $33.33 \%$ (2 cases) were diagnosed. Similar study carried by Berghoff ${ }^{11}$, Coco \& Bergrada ${ }^{12}$ and Catovic ${ }^{13}$ 
diagnosed $45.4 \%, 67.2 \%$ and $63.8 \%$ respectively. Observed lower value in our study could be due to failure to detect minor deletions of X chromosome. In children with Turner syndrome, the proportion of pure Turner syndrome karyotype $(45, \mathrm{X})$ and mosaic Turner syndrome karyotype $(45, \mathrm{X} / 46, \mathrm{XX})$ was equal (1 each). Similar pattern of result was obtained by Mokhtar ${ }^{14}$ and Higurashi et $a l^{15}$ who obtained a single child with $45, \mathrm{X}$ karyotype among 185 suspected cases for chromosomal disorder. However several studies had documented pure Turner syndrome karyotype in $44.4 \%$ to $63.3 \%$ and mosaic Turner syndrome karyotype in $10.9 \%$ to $26.6 \%$ of cases diagnosed for Turner syndrome $e^{11,12,13}$.

Regarding congenital malformations the present study included 12 children with cleft palate, congenital cataract, microcephaly, high arched palate, common urogenital sinus with ectopic anus, ambiguous genitalia and other different malformations in which exact chromosomal disorder couldn't be suspected. The cytogenetic analysis of these cases didn't reveal any chromosomal disorders. This may be due to micro deletion or micro duplication of chromosome, which was not feasible to detect at this set up. However, studies had reported that only $6-7 \%$ of congenital malformations are caused by chromosomal disorders ${ }^{16,17}$, about $27-33 \%$ are attributed by Multifactorial and other single gene disorders and $7-10 \%$ had environmental cause ${ }^{17}$.

\section{Conclusion}

Hence, chromosomal disorder was diagnosed in $33.24 \%$ of children suspected with genetic disorder in which Down syndrome predominated (26.67\%) followed by Turner syndrome (6.67\%). These findings suggest that cytogenetic analysis is useful tool to confirm and modify clinical diagnosis in children with suspected chromosomal syndromes and clinically undiagnosed syndromes.

\section{References}

1. Mattheis P. Diagnosing Down syndrome. In: Redfern DE. Caring for individuals with Down syndrome and their families: report of the Third Ross Roundtable on critical issues in Family medicine in collaboration with Society of Teachers of family Medicine. Columbus, Ohio: Ross products division, Abbott laboratories; 1995. P 1-13.

2. Pueschel SM. Phenotypic characteristics. In: Pueschel SM, Pueschel JK. Biomedical concerns in persons with Down syndrome. Baltimore: Brookes; 1992. P 1-12.

3. Holzgreve W, Nippert I, Ganshirt-Ahlert D, Schloo R, Miny P. Immediate and long-term applications of technology. Clin Obstet Gynecol 1993;36:476-84.
4. Cortes F, Alliende M, Curotto B. Cytogenetic findings in patients with Down's syndrome. Rev Chil Pediatr 1990;61(6):313-6.

5. Astete C, Youlton R, Castillo S, Be C, Daher V. Clinical and cytogenetic analysis of 257 cases of Down's syndrome. Rev Chil Pediat 1991;62(2):99-102.

6. Rimion DL, Connor JM, Pyeritz RE, Korf BR. Emery and Rimion's Principles and Practice of Medical Genetics. $4^{\text {th }}$ edition. Edinburgh: Churchill Living stone; 2002. P 690-1201.

7. Lindsten J, Marsk L, Berglund K, Iselius L, Ryman N, Anneren G et al. Incidence of Down's syndrome in Sweden during the years 1968-1977. Hum Genet Suppl 1981;2:195-210.

8. Thomas IM, Rajangam S, Hegde S. Cytogenetic investigations in Down syndrome patients \& their parents. Indian J Med Res 1992;96:36671.

9. Al-awadi SA, Farag TI, Teebi AS, Naguib KK, Sundareshan TS, Murthy DS. Down syndrome in Kuwait. Am J Med Genet Suppl 1990;7:87-8.

10. Ikeda Y. An anthropometric study of girls with Ulrich Turner syndrome. American journal of human genetics 1982;12:271-80.

11. Berghoff R, Rudiger RA, passarge E. Cytogenetic and clinical findings in suspected Turner's syndrome: results of a five-year study of 207 patients. Dtsch Med Wochenschr 1976;101(14):532-7.

12. Coco R, Bergada C. Cytogenetic findings in 125 patients with Turner's syndrome and abnormal karyotypes. J Genet Hum 1977;25(2):95-107.

13. Catovic A. Cytogenetic findings at Turner Syndrome and their correlation with clinical findings. Bosn J Med Sci 2005;5(3):54-8.

14. Mokhtar MM. Chromosomal aberrations in children with suspected genetic disorders. Eastern Mediterranean Health Journal 1973;1:114-22.

15. Higurashi M, Iijima K, Ikeda U. Chromosome survey of newborn infants in Tokyo: follow-up study for XXY. Birth Defects Orig Artic Ser 1979;15(1):161-74.

16. Kalter H, Warkany J. Medical Progress: congenital malformations: etiological factors and their role in prevention. $\mathrm{N}$ Eng $\mathrm{J}$ Med 1983;308:491-7.

17. Moore KL, Persaud TVN. Moore Persaud "The Developing Human" clinically oriented embryology. $7^{\text {th }}$ Edition. New Delhi: Elsevier; 2005. P 157-85. 